\title{
Effects of Musca domestica Cecropin on the Adhesion and Migration of Human Hepatocellular Carcinoma BEL-7402 Cells
}

\author{
Xiao-bao Jin, ${ }^{a, b, \#}$ Han-fang Mei, ${ }^{a, b, \#}$ Qiao-hong Pu, ${ }^{a, b}$ Juan Shen, ${ }^{a, b}$ Xue-mei Lu, ${ }^{a, b}$ \\ Fu-jiang Chu, ${ }^{a, b}$ and Jia-yong Zhu* ${ }^{* a, b}$ \\ ${ }^{a}$ School of Basic Courses, Guangdong Pharmaceutical University; Guangzhou 510006, China: and ${ }^{b}$ Guangdong \\ Province Key Laboratory of Pharmaceutical Bioactive Substances; Guangzhou 510006, China. \\ Received October 24, 2012; accepted March 12, 2013; advance publication released online March 18, 2013
}

This study was designed to explore the effects of Musca domestica antimicrobial peptides cecropin on the adhesion and migration of human hepatocellular carcinoma BEL-7402 cells. The adhesive and migratory capacities were determined by adhesion assay and transwell assay, respectively. The changes in microvilli of tumor cells were determined by scanning electron microscopy (SEM). Western blotting and quantitative polymerase chain reaction (qPCR) were carried out to determine the expression levels of proteins related to adhesion and migration, such as matrix metalloproteinase-2 (MMP2), tissue inhibitors of metalloproteinase-2 (TIMP2), and epithelial cadherin (E-cadherin). We found that Musca domestica cecropin inhibited the adhesion and migration of BEL-7402 cells, which also displayed curling microvilli, increased ball structures on cell surface, gradually broken connections between tumor cells, and even disappeared microvilli on some cells. The expression of $M M P 2$ was significantly reduced after cecropin treatment, while the levels of $T I M P 2$ and $E$-cadherin were significantly increased. These results suggest that Musca domestica cecropin inhibits the adhesion and migration of human hepatocellular carcinoma BEL-7402 cells by destroying the microvilli of tumor cells and changing the expression of MMP2, TIMP2 and E-cadherin.

Key words Musca domestica; cecropin; human hepatocellular carcinoma; adhesion; migration

The cecropins are a family of antimicrobial peptides that were first isolated by Boman et al. from the Hyatophora cecropia pupae. ${ }^{1,2)}$ They are able to form specific amphipathic alpha-helices, which allow them to target nonpolar lipid cell membranes, and have strong antibiotic activity against both Gram-positive and Gram-negative bacteria at low micromolar concentrations. ${ }^{3,4)}$ More recent studies have also indicated the antitumor activity of cecropins against various cancer cell lines of leukemia, lymphoma, colon carcinoma, small cell lung cancer and gastric cancer, but without damage to human normal cells which would make it a good candidate for the development of anti-tumor agents. ${ }^{5,6)}$

The Musca domestica gene cecropin (GenBank accession number: EF175878) was cloned in our laboratory from the larva." We have also shown that it inhibits the proliferation and promotes the apoptosis of human hepatocellular carcinoma BEL-7402 cells, human lung cancer A549 cells, human breast cancer MCF-7 cells and human cervical cancer HeLa cells without affecting the normal liver cells. In these cancer cells, the hepatomcellular carcinoma cell line BEL-7402 is the most sensitive to cecropin. ${ }^{89}$ Proliferation, adhesion and migration are important biological characteristics of tumor cells. In this study, we explored whether Musca domestica antimicrobial peptide cecropin affects the adhesive and migratory capacities of human hepatocellular carcinoma BEL-7402 cells and the underlying mechanism.

\section{MATERIALS AND METHODS}

Preparation of Musca domestica Antimicrobial Peptide Cecropin The Musca domestica cecropin was expressed through the COS-7 eukaryotic expression system and puri-

\footnotetext{
The authors declare no conflict of interest.

\# These authors contributed equally to this work.
}

fied to reach $99 \%$ purity identified by HPLC using a nickelchelating Sepharose column as described previously. ${ }^{10)}$ Its amino acid sequence is MNFNKLFVFVALVLAVCIGQSEAG WLKKIGKKIERVGQHTRDATIQTIGVAQQAANVAA TLKG. The peptide was dissolved in RPMI 1640 medium at $500 \mathrm{~mm}$ and sterilized by filtration through a $0.2 \mathrm{~mm}$ filter before experiments.

Adhesion Assay Each well of 96-well plates was precoated overnight at $4^{\circ} \mathrm{C}$ with $50 \mathrm{mg} / \mathrm{mL}$ FN (Laboratory of Cell Biology, Health Scientific Center of Peking University, China) and blocked with $10 \mathrm{mg} / \mathrm{mL}$ bovine serum albumin (BSA). With or without $24 \mathrm{~h}$ of cecropin treatments at different concentrations at $37^{\circ} \mathrm{C}$, about $3.0 \times 10^{5} /$ well human hepatocellular carcinoma BEL-7402 cells were seeded into 6-well plates. The next day, the BEL-7402 cells were resuspended in RPMI 1640, plated into the precoated 96 -well tissue plates $\left(2.0 \times 10^{3}\right.$ cells/ well), and incubated at $37^{\circ} \mathrm{C}\left(5 \% \mathrm{CO}_{2}\right)$ for $1 \mathrm{~h}$. The supernatant was replaced by new RPMI 1640, and the plates were chilled on ice for $10 \mathrm{~min}$ before being photographed. Then the supernatant was removed, and cell layers were washed with phosphate buffered saline (PBS) and incubated with 3-(4,5-dimethylthiazol-2-yl)-2,5-diphenyltetrazolium bromide (MTT) $(50 \mu \mathrm{L}, 0.5 \mathrm{mg} / \mathrm{mL})$ in RPMI 1640 without fetal bovine serum for $4 \mathrm{~h}$ at $37^{\circ} \mathrm{C}$. The cell culture was centrifuged at $1000 \times \boldsymbol{g}$ for $5 \mathrm{~min}$ before the supernatant was discarded. Subsequently, $150 \mu \mathrm{L}$ of dimethyl sulfoxide (DMSO) was added to dissolve the formazan crystals formed in cells. The optical density (OD) was then measured by a microplate reader (Thermo Molecular Devices Co., Sunnyvale, U.S.A.) at $570 \mathrm{~nm}$. The cell adhesion rate was calculated as: cell adhesion rate $=(O D$ value of experimental group/control group OD value) $\times 100 \%$. The assay was repeated three times for each sample.

Migration Assay The Transwell migration assay was performed with modified Boyden Chambers containing polycarbonate membranes ( $8 \mu \mathrm{m}$ pores, Costar) as described previ- 
ously. ${ }^{11)}$ Both sides of the membrane were coated and air-dried with $10 \mu \mathrm{L}$ fibronectin (FN, $1 \mathrm{mg} / \mathrm{mL}$ ) before being placed into 24-well plates. With or without $24 \mathrm{~h}$ treatments of cecropin at different concentrations at $37^{\circ} \mathrm{C}$, about $3.0 \times 10^{5} /$ well BEL-7402 cells were seeded into 6 -well plates. The next day, the cells were added to the upper chamber at $2 \times 10^{5}$ cells/well, and the lower chamber was filled with RPMI 1640 containing $4 \mu \mathrm{g} / \mathrm{mL}$ FN1. After $6 \mathrm{~h}$ incubation at $37^{\circ} \mathrm{C}\left(5 \% \mathrm{CO}_{2}\right)$, the membrane was fixed in methanol, and the cells on the upper surface were mechanically removed. The migrated cells on the lower side of the membrane were stained with Giemsa and photographed under a light microscope at $\times 200$ magnification. Four random microscopic fields were counted per membrane, and three membranes from each group were analyzed at the same time. Other cells that migrated and attached to the lower surface of the filter were trypsinized and resuspended in $300 \mu \mathrm{L}$ RPMI 1640 medium. The cell suspension was added to 96-well plates with each well containing $100 \mu \mathrm{L}$ RPMI 1640 and $50 \mu \mathrm{L}$ MTT $(0.5 \mathrm{mg} / \mathrm{mL})$. Four hours later, the supernatant was discarded, and $150 \mu \mathrm{L}$ DMSO was added to solubilize the formazan crystals formed in cells. Finally, the absorbance was measured colorimetrically at $570 \mathrm{~nm}$. The cell migration rate was calculated with the OD values of non-migrated and migrated cells. The rate of migration $=\mathrm{OD}_{\text {mig }} /\left(\mathrm{OD}_{\text {mig }}+\mathrm{OD}_{\text {non }}\right) \times 100 \%$, where $\mathrm{OD}_{\text {mig }}$ is the $\mathrm{OD}$ value of migrated cells and $\mathrm{OD}_{\text {non }}$ is the OD value of non-migrated cells. The assay was repeated three times for each sample.

Scanning Electron Microscopy $3 \times 10^{4}$ BEL-7402 cells in $2 \mathrm{~mL}$ RPMI 1640 were seeded into 6-well plates, in which each well contained one cover glass that allowed cells to crawl growth at $37^{\circ} \mathrm{C}$ overnight. The next day, cecropin was added to a final concentration of $50 \mu \mathrm{M}$, and the mixture was incubated for $24 \mathrm{~h}$. The cover glasses were then removed from the plate, washed with PBS, fixed with $2.5 \%$ glutaraldehyde (Sigma, St. Louis, U.S.A.) for $30 \mathrm{~min}$, and re-washed with PBS. They were re-fixed with $1 \%$ osmic acid (Sigma) for $30 \mathrm{~min}$ and washed with PBS. The dehydration was done in $50 \%, 70 \%$ and $90 \%$ ethanol (Sigma) for $20 \mathrm{~min}$ with each concentration. Then the cover glasses were put into isoamyl acetate (Sigma) for $30 \mathrm{~min}$ and placed at $4^{\circ} \mathrm{C}$ overnight. The next day, all cover glasses were observed under a scanning electron microscope (Zeiss, Berlin, Germany). The experiment was repeated three times for each sample.

Western Blot Analysis Detection of Matrix Metalloproteinase (MMP2), Tissue Inhibitors of Metalloproteinase-2 (TIMP2) and E-Cadherin Expression Cultures of BEL-7402 cells at approximately $80 \%$ confluence were treated with $25,50,100 \mu \mathrm{M}$ cecropin for $24 \mathrm{~h}$, and no cecropin was present in the control well. Cells were then harvested and placed in $1 \mathrm{~mL}$ lysis buffer (1\% Triton X-100, $0.5 \%$ sodium deoxycholate, $0.5 \mathrm{mg} / \mathrm{mL}$ leupetin, $1 \mathrm{~mm}$ ethylenediaminetetraacetic acid, $1 \mathrm{mg} / \mathrm{mL}$ pepstatin, and $0.2 \mathrm{~mm}$ phenylmethylsulfonyl fluoride). The protein concentration was determined by the bicinchoninic acid method (Pierce, Rockford, IL, U.S.A.), and $20 \mu \mathrm{g}$ of protein was loaded onto $15 \%$ polyacrylamide gel electrophoresis-sodium dodecyl sulfate gel (Invitrogen, Carlsbad, CA, U.S.A.), separated by electrophoresis, and transferred to a polyvinylidene difluoride membrane. The membranes were blocked with $5 \%$ nonfat milk and $1 \%$ polyvinylpyrrolidone in PBS for $30 \mathrm{~min}$ and then incubated for $1 \mathrm{~h}$ with $1 \mathrm{mg} / \mathrm{mL}$ antibodies to $M M P 2, T I M P 2, E$-cadherin and $\beta$-tubulin (Santa Cruz, CA, U.S.A.). Then the membrane was incubated for $1 \mathrm{~h}$ with a peroxidase-conjugated antibody (Santa Cruz, CA, U.S.A.) for $1 \mathrm{~h}$ at room temperature after washing. Final detection was accomplished with Western blot luminol reagent (SC-2048; Santa Cruz, CA, U.S.A.) as described by the manufacturer. The density of target bands was quantified by the computer-aided 1-D gel analysis system. The experiment was repeated three times for each sample.

Quantitative Polymerase Chain Reaction (qPCR) Detection of MMP2, TIMP2 and E-Cadherin Expression Cultures of BEL-7402 cells at approximately $80 \%$ confluence were treated with $25,50,100 \mu \mathrm{M}$ cecropin for $24 \mathrm{~h}$, and no cecropin was present in the control well. Cells were harvested and RNA was extracted using Trizol (Life Technologies, Gaithersburg, MD, U.S.A.). Aliquot of $2 \mu \mathrm{g}$ total RNA was transcribed reversely using MMLV reverse transcriptase (Promega, Madison, WI, U.S.A.). cDNA samples were subjected to qPCR using Thunderbird SYBR qPCR Mix (TOYOBO, Osaka, Japan) according to the manufacturer's instructions on a Miniopticon qPCR detection system (Bio-Rad). Data collection and analysis was performed with Opticon3.0 software (Bio-Rad). $\beta$-Tubulin gene was used as an endogenous control. Oligonucleotide primers used for qPCR were synthesized by Shanghai Biotechnology Co., Ltd. (Shanghai, China) and as follows: MMP2 gene (Accession No. NM 004530), sense-5'-ATGGAGGCGCTA ATG GCC CG-3' and antisense-5'-GCC AAC TCT TTG TCC GT-3'; TIMP2 gene (Accession No. NM_003255), sense-5'-ATG GGCGCCGCGGCCCGC AC-3' and antisense-5'-GTC ATC ACT ACA TCTGCA T-3'; E-cadherin gene (Accession No. Z18923), sense-5'-ATG GGC CCT TGG AGCCGC AGC - $3^{\prime}$ and antisense-5'-CGT GAA CGT GTA GCTCTC G-3'; $\quad \beta$-tubulin gene (Accession No. NM_177987), sense-5'-ATGAGGGAG ATC GTGCTC ACG -3' and antisense-5'-GAT GCGCTCCAG CTGCAG-3'. The experiment was repeated three times for each sample.

Statistical Analysis The data are presented as the mean \pm S.D. and analyzed with SPSS 11.0 using the one-way ANOVA least significance difference statistical analysis method. A difference was determined as statistically significant when $p<0.05$.

\section{RESULTS}

Effects of Cecropin on the Adhesion of BEL-7402 Cells The adhesion of BEL-7402 cells was determined with MTT assay, along with CCD camera imaging that monitored the adhered cells. As shown in Fig. 1, Musca domestica cecropin inhibited significantly the adhesion ability of human hepatocellular carcinoma BEL-7402 cells at $25-100 \mu \mathrm{M}$ in a dosedependent manner. The adhesion rates after $24-\mathrm{h}$ treatments of 25,50 and $100 \mu \mathrm{M}$ cecropin were $68.6 \pm 1.1 \%, 56.4 \pm 1.3 \%$ and $44.5 \pm 0.9 \%$ as compared with control, respectively.

Effects of Cecropin on the Migration of BEL-7402 Cells To test whether cecropin inhibits migration of human hepatocellular carcinoma cells, the transwell assay was performed. To rule out the possibility that decreased cell migration after cecropin treatment might be caused by decreased total cell number, in fact, the rate of migration was expressed as $\mathrm{OD}_{\text {mig }} /$ $\left(\mathrm{OD}_{\text {mig }}+\mathrm{OD}_{\text {non }}\right) \times 100 \%$, where $\mathrm{OD}_{\text {mig }}$ is the $\mathrm{OD}$ value of migrated cells and $\mathrm{OD}_{\text {non }}$ is the $\mathrm{OD}$ value of non-migrated cells. 

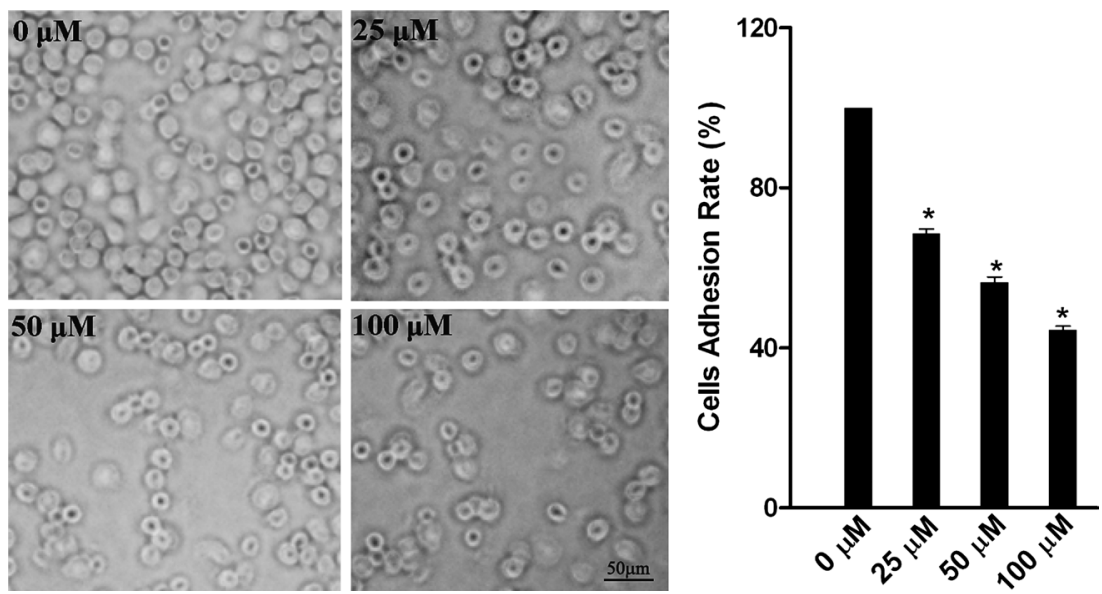

Fig. 1. Adhesion Assay of BEL-7402 Cells Treated with 25, 50 and $100 \mu \mathrm{M}$ Cecropin

After $24 \mathrm{~h}$ treatments, the cell adhesion rate was measured. The number of adhered cells was captured by CCD camera imaging and assessed by MTT assay. Data are presented as the mean \pm S.D. from three repeated assays. ${ }^{*} p<0.05$ compared with the control group (without cecropin). Magnification, $200 \times$.
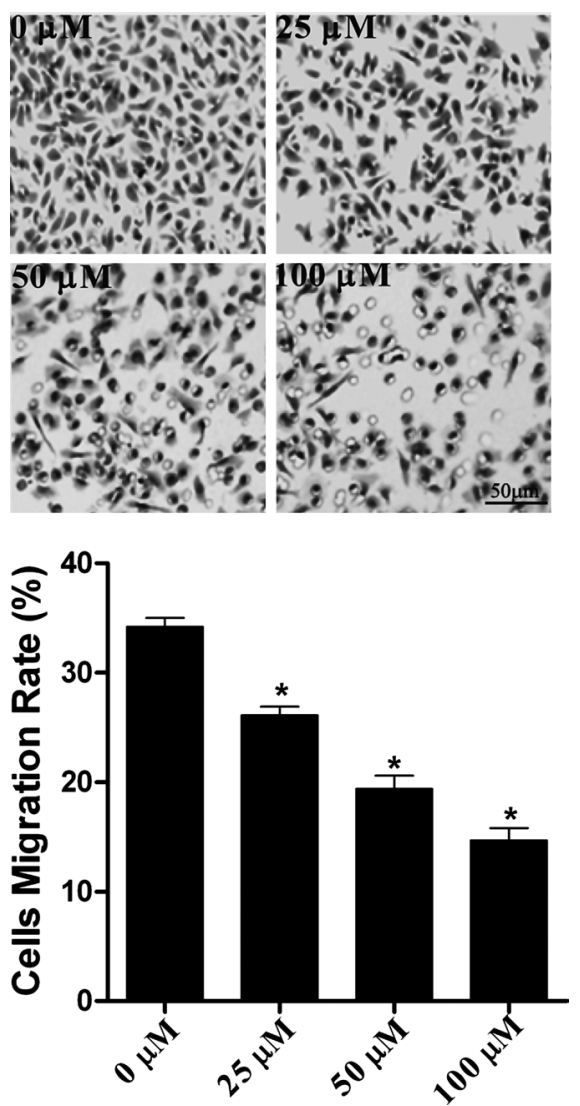

Fig. 2. Migration Assay of BEL-7402 Cells Treated with 25, 50 and $100 \mu \mathrm{M}$ Cecropin

BEL-7402 cells were seeded into the upper compartment of transwell chambers for migration assay after $24 \mathrm{~h}$ treatments of cecropin at different concentrations. The rate of cell migration was measured by MTT assay, and the number of migrated cells was captured by CCD camera imaging $(200 \times)$. Data are presented as the mean \pm S.D. from three repeated assays. ${ }^{*} p<0.05$ compared with the control group (without cecropin). Magnification, 200×

The OD values were determined by MTT assay. Figure 2 showed that cecropin treatment led to concentration-dependent decrease in cell migration after 24-h incubation. The rates of migration were $34.2 \pm 0.8 \%, 26.1 \pm 0.8 \%, 19.4 \pm 1.2 \%$, and $14.7 \pm$ $1.1 \%$ after $24-\mathrm{h}$ treatment of $0,25,50$ and $100 \mu \mathrm{M}$ cecropin, respectively.

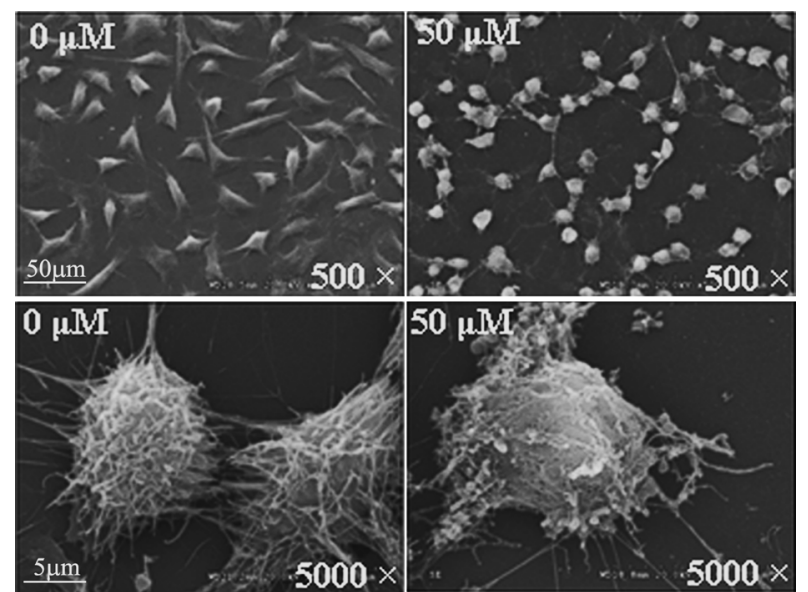

Fig. 3. Scanning Electron Microscopy of BEL-7402 Cells Treated with $50 \mu \mathrm{m}$ Cecropin

After $24 \mathrm{~h}$ treatment of $50 \mu \mathrm{m}$ cecropin, the cell morphology was observed under scanning electron microscope at different magnifications. The surface microvilli of cells treated with $50 \mu \mathrm{m}$ cecropin displayed significant changes compared with the control group.

Effects of Cecropin on the Morphology of BEL-7402 Cells The electronic microscopy assay showed that the control BEL-7402 cells had integral cell membrane with rich microvilli, curl plexiform, regular arrays, and filament distribution. However, cecropin treatment resulted in cell body shrinkage, curling and distorting surface microvilli, gradually increasing ball structure, gradually breaking cell connections, widening cell gaps, and missing parts of cell surface microvilli (Fig. 3).

Effects of Cecropin on the Expression of MMP2, TIMP2 and $\boldsymbol{E}$-Cadherin To explore the underlying mechanism for cecropin-induced inhibition of the adhesion and migration of BEL-7402 cells, we sought to determine the effects of cecropin on the expression of two common migration-related proteins $M M P 2$ and $T I M P 2$, as well as the adhesion-related protein E-cadherin. As shown in Fig. 4A, Western blotting assay revealed that after $24 \mathrm{~h}$ treatment, cecropin $(25-100 \mu \mathrm{M})$ dose-dependently suppressed the expression of $M M P 2$, whereas increased the expression of TIMP2 and E-cadherin significantly. To confirm the effect of cecropin on the expression of 
A
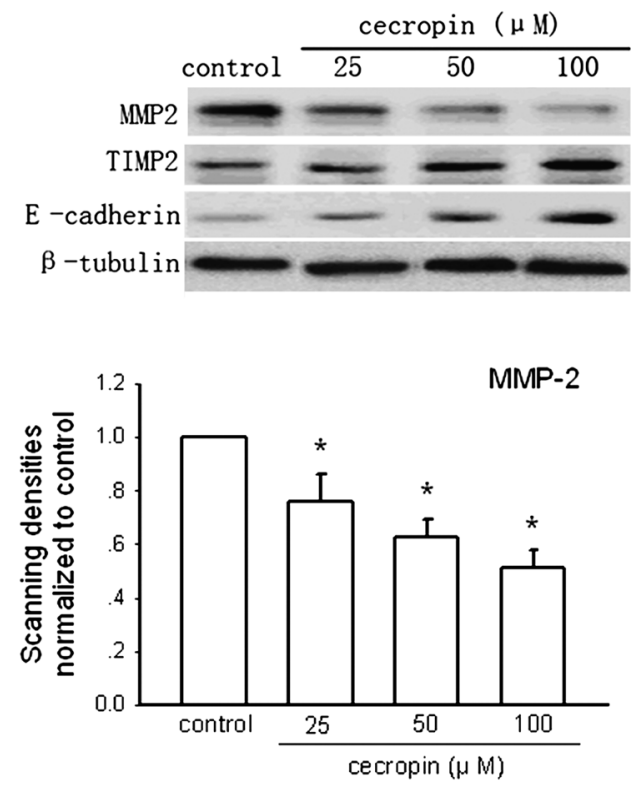

TIMP-2
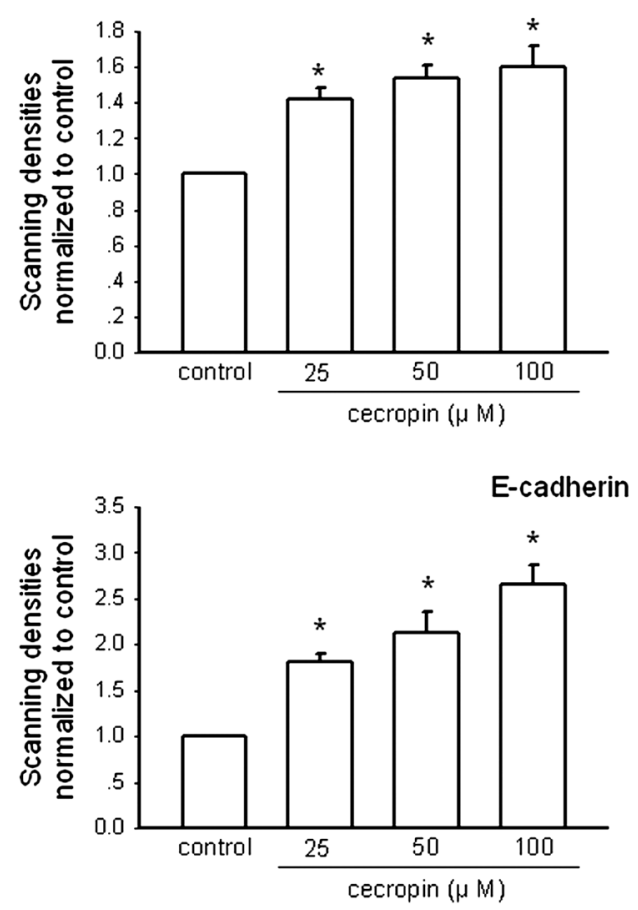

$\mathrm{B}$
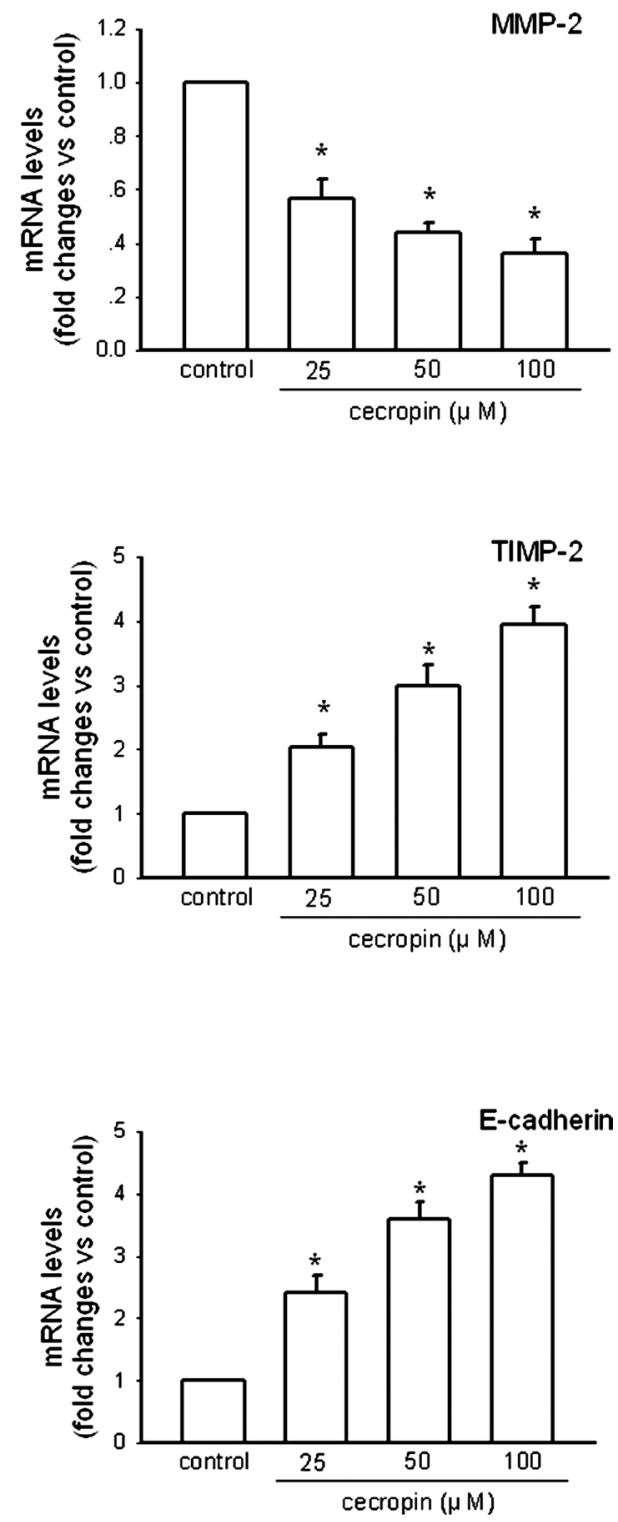

Fig. 4. The Effects of Cecropin on the Expression of MMP2, TIMP2 and E-Cadherin after 24h Incubation

(A) Western blotting showing effects of cecropin at indicated concentrations on $M M P 2, T I M P 2$ and E-cadherin expression. Bar graphs are derived from densitometric scanning of the blots. Bars are mean \pm S.D. from three independent experiments. * Significantly different from control, $p<0.05$. (B) qPCR results showing effects of cecropin at indicated concentrations on $M M P 2, T I M P 2$ and E-cadherin mRNAs expression. Bars are mean \pm S.D. from four independent experiments. $*$ Significantly different from control, $p<0.05$.

these proteins at the transcription level or post-transcription level, we performed qPCR assay to determine the effect of cecropin on MMP2, TIMP2 and E-cadherin mRNA levels after $24 \mathrm{~h}$ treatment. Figure $4 \mathrm{~B}$ showed that consistent with the expression trends in Western blotting assay, cecropin administration significantly reduced the mRNA levels of $M M P 2$, while enhanced the mRNA levels of TIMP2 and E-cadherin in a concentration-dependent manner. Therefore, there results suggest that cecropin affects the expression of MMP2, TIMP2 and $E$-cadherin probably at the transcription level.

\section{DISCUSSION}

Adhesion is the initiating step of cell migration and thus directly affects tumor metastasis. ${ }^{12}$ The adhesion in tumor migration and metastasis involves specific receptors or nonspecific cell surface receptors and matrix components, such as laminin ( $\mathrm{LN}$, in the basement membrane), fibronectin ( $\mathrm{FN}$, in the extracellular matrix), and type IV collagen. During the process of adhesion, migrating tumor cells or their surrounding local cells secrete some enzymes to degrade local matrix 
to facilitate the chemotactic movement of tumor cells. This process is repeated continuously with outward expansion and invasion of tumor cells. ${ }^{13)} \mathrm{FN}$ plays an important role in adhesion as a major component of the extracellular matrix and basement membrane. In this study, we used FN to simulate the extracellular matrix in vitro and observed that Musca domestica cecropin inhibited the adhesion and migration of BEL-7402 cells (Figs. 1, 2).

The microvilli of tumor cells, normally intensive and long, play a key role in response to environmental changes and in their adhesion, migration and metastasis. They mediate the exchange of materials with the outside world to facilitate the malignant proliferation and attachment of tumor cells. ${ }^{14)}$ In this study, we observed shrinking tumor cell body, curling and distorted surface microvilli, gradually increasing ball structure, gradually breaking connections between cells, widened cell gaps, and missing parts of the cell surface microvilli with treatments of Musca domestica cecropin (Fig. 3). This may contribute to the inhibited adhesion and migration of BEL-7402 cells by cecropin.

Tumor invasion and metastasis are complex processes, among which the adhesion of tumor cells to the extracellular matrix (ECM), ECM degradation, and the migration of tumor cells in the degradated matrix are critical. ${ }^{15)}$ Therefore, ECM is a natural barrier to the invasion and metastasis of tumor cells. ${ }^{16)}$ The degradation enzymes secreted by tumor cells or local cells include matrix metalloproteinase (MMPs), plasminogen activator, and cysteine protease. ${ }^{17)} M M P s$ can be expressed and secreted by both tumor cells and stromal cells, and their activity is regulated by tissue inhibitors, TIMPs. ${ }^{18)}$ The balance between MMPs and TIMPS is important for tumor cell invasion and metastasis, and $M M P 2$ and TIMP2 are two critical members in these two families. ${ }^{19)}$ In this study, we discovered that cecropin inhibited tumor cell migration rates in a dose-dependent manner, probably through the reduced expression of MMP2 and increased expression of TIMP2.

Tumor cell invasion and metastasis require many times of adhesion to accomplish, which is tightly regulated by cell adhesion molecules. Two critical such factors are cadherins and integrins. ${ }^{20)}$ E-Cadherin is a classical member of the cadherin superfamily II, which requires extracellular calcium ions to mediate adhesion. ${ }^{21)}$ It has been shown that reduced expression of E-cadherin negatively affects cell adhesion. ${ }^{22)}$ Furthermore, exogenous expression of E-cadherin in some malignant tumors was able to significantly reduce tumor cell adhesion and metastasis. ${ }^{23)}$ Integrin $\beta 1$ is a transmembrane protein composed of $\alpha$ and $\beta$ subunits that are connected by disulfide bonds. It can form the ligand-integrin $\beta 1$-cytoskeleton transmembrane information system with cell matrix and cytoskeleton components to mediate tumor cell adhesion and metastasis. $^{24)}$ Therefore, reduced expression level of integrin $\beta 1$ may suppress the migration ability of tumor cells. In this study, we observed significant increases in the expression level of E-cadherin with Musca domestica cecropin treatments, but the expression level of integrin $\beta 1$ was not affected (data not shown). This indicates that cecropin inhibits tumor cell adhesion through regulation of E-cadherin expression.

In summary, we observed in this study that Musca domestica cecropin inhibits tumor cell adhesion and migration. Cecropin treatments also cause destruction of tumor cell microvilli, up-regulation of TIMP2 and E-cadherin, and down-regu- lation of $M M P 2$, which may contribute to cecropin's inhibitory effects on adhesion and migration of human hepatocellular carcinoma BEL-7402 cells. In the future, we will investigate in vivo to further explore Musca domestica cecropin's effects on tumor adhesion and migration.

Acknowledgments This work was supported by Grants from the National Natural Science Foundation of China (No. 30671832) and the Guangdong Province Science and Technology Foundation (No. 2010B031200011).

\section{REFERENCES}

1) Boman HG, Nilsson-Faye I, Paul K, Rasmuson T Jr. Insect immunity. I. Characteristics of an inducible cell-free antibacterial reaction in hemolymph of Samiacynthia pupae. Infect. Immun., 10, 136-145 (1974).

2) Steiner H, Hultmark D, Engström A, Bennich H, Boman HG. Sequence and specificity of two antibacterial proteins involved in insect immunity. Nature, 292, 246-248 (1981).

3) Duvic B, Jouan V, Essa N, Girard PA, Pagès S, Abi Khattar Z, Volkoff NA, Givaudan A, Destoumieux-Garzon D, Escoubas JM. Cecropins as a marker of Spodoptera frugiperda immunosuppression during entomopathogenic bacterial challenge. J. Insect Physiol., 58, 881-888 (2012)

4) Lu XM, Jin XB, Zhu JY, Mei HF, Ma Y, Chu FJ, Wang Y, Li XB. Expression of the antimicrobial peptide cecropin fused with human lysozyme in Escherichia coli. Appl. Microbiol. Biotechnol., 87, 2169-2176 (2010).

5) Jin XB, Li XB, Zhu JY, Lu XM, Shen J, Chu FJ, Mei HF. The target of Musca domestica cecropin on human hepatocellular carcinoma BEL-7402 cells. Zhongguo Ji Sheng Chong Xue Yu Ji Sheng Chong Bing Za Zhi, 29, 271-273 (2011).

6) Stuttmann H, Retz M, Paulsen F, Harder J, Zwergel U, Kamradt J, Wullich B, Unteregeer G, Stöckle M, Lehmann J. Antimicrobial peptides of the cecropin-family show potent antitumor activity against bladder cancer cells. BMC Urol., 8, 1-7 (2008).

7) Jin XB, Xu QY, Xu JH, Zhu JY. Cloning and sequence analysis of the cDNA encoding cecropin an antimicrobial peptide from $\mathrm{Musca}$ domestica larvae. Re Dai Yi Xue Za Zhi, 5, 903-906 (2004).

8) Jin XB, Mei HF, Li XB, Ma Y, Zeng AH, Wang Y, Lu XM, Chu FJ, Wu Q, Zhu JY. Apoptosis-inducing activity of the antimicrobial peptide cecropin of Musca domestica in human hepatocellular carcinoma cell line BEL-7402 and the possible mechanism. Acta Biochim. Biophys. Sin. (Shanghai), 42, 259-265 (2010).

9) Jin XB, Gong SM, Pu QH, Zhu JY, Chu FJ, Mei HF. Influence of antimicrobial peptide cecropin of Musca domestica on proliferation and apoptosis of human tumor cell. Re Dai Yi Xue Za Zhi, 12, 293-295 (2011).

10) Jin XB, Zhu JY, Ma Y, Liu LS. The expression of antibacterial peptide cecropin gene in COS-7 cells and the preliminary study on the activities of its gene product. Chin. J. Zoonoses, 23, 566-568 (2007).

11) Doroshenko P, Sabanov V, Doroshenko N. Cell cycle-related changes in regulatory volume decrease and volume-sensitive chloride conductance in mouse fibroblasts. J. Cell. Physiol., 187, 65-72 (2001).

12) Yamasaki T, Seki N, Yamada Y, Yoshino H, Hidaka H, Chiyomaru T, Nohata N, Kinoshita T, Nakagawa M, Enokida H. Tumor suppressive microRNA-138 contributes to cell migration and invasion through its targeting of vimentin in renal cell carcinoma. Int. J. Oncol., 41, 805-817 (2012).

13) Pathak A, Kumar S. Independent regulation of tumor cell migration by matrix stiffness and confinement. Proc. Natl. Acad. Sci. U.S.A., 109, 10334-10339 (2012). 
14) Xiang Z, Bai-he H, Xin-rong Z, Zhang H. Relationship of microvillus-like protrusions to extracellular membrane particles and tunneling nanotubes on the surfaces of human fetal and hepatocellular carcinoma cells revealed by a scanning electron microscope. Journal of Clinical Rehabilitative Tissue Engineering Research, 14, 6785-6789 (2010).

15) Barlow M, Edelman M, Glick RD, Steinberg BM, Soffer SZ. Celecoxib inhibits invasion and metastasis via a cyclooxygenase 2-independent mechanism in an in vitro model of Ewing sarcoma. $J$. Pediatr. Surg., 47, 1223-1227 (2012).

16) Leeming DJ, Bay-Jensen AC, Vassiliadis E, Larsen MR, Henriksen K, Karsdal MA. Post-translational modifications of the extracellular matrix are key events in cancer progression: opportunities for biochemical marker development. Biomarkers, 16, 193-205 (2011).

17) Libra M, Scalisi A, Vella N, Clementi S, Sorio R, Stivala F, Spandidos DA, Mazzarino C. Uterine cervical carcinoma: role of matrix metalloproteinases (review). Int. J. Oncol., 34, 897-903 (2009).

18) Moore CS, Crocker SJ. An alternate perspective on the roles of TIMPs and MMPs in pathology. Am. J. Pathol., 180, 12-16 (2012).

19) Srivastava P, Lone TA, Kapoor R, Mittal RD. Association of promoter polymorphisms in MMP2 and TIMP2 with prostate cancer susceptibility in North India. Arch. Med. Res., 43, 117-124 (2012).

20) Martinez-Rico C, Pincet F, Thiery JP, Dufour S. Integrins stimulate E-cadherin-mediated intercellular adhesion by regulating Src-kinase activation and actomyosin contractility. J. Cell Sci., 123, 712-722 (2010)

21) Singhai R, Patil VW, Jaiswal SR, Patil SD, Tayade MB, Patil AV. E-Cadherin as a diagnostic biomarker in breast cancer. N. Am. J. Med. Sci., 3, 227-233 (2011).

22) Brasch J, Harrison OJ, Honig B, Shapiro L. Thinking outside the cell: how cadherins drive adhesion. Trends Cell Biol., 22, 299-310 (2012).

23) Sawada K, Mitra AK, Radjabi AR, Bhaskar V, Kistner EO, Tretiakova M, Jagadeeswaran S, Montag A, Becker A, Kenny HA, Peter ME, Ramakrishnan V, Yamada SD, Lengyel E. Loss of E-cadherin promotes ovarian cancer metastasis via alpha 5-integrin, which is a therapeutic target. Cancer Res., 68, 2329-2339 (2008).

24) Fransvea E, Mazzocca A, Antonaci S, Giannelli G. Targeting transforming growth factor (TGF)-betaRI inhibits activation of betal integrin and blocks vascular invasion in hepatocellular carcinoma. Hepatology, 49, 839-850 (2009). 